\title{
RESEARCH
}

Open Access

\section{Formula feeding practice and associated factors among mothers with infants $0-6$ months of age in Addis Ababa, Ethiopia: a community-based cross-sectional study}

Alemnesh Abebe Taye ${ }^{1}$, Wondwosen Asegidew ${ }^{1}$, Mitku Mammo Taderegew ${ }^{2 *}$, Yonas Girma Bizuwork ${ }^{3}$ and Betregiorgis Zegeye ${ }^{4}$

\begin{abstract}
Background: Lack of exclusive breastfeeding during the first half-year of life is an important risk factor for childhood morbidity and mortality. Despite this, less than $40 \%$ of infants below 6 months are exclusively breastfed worldwide. This is because breastfeeding is declining and being replaced by formula feeding. Nowaday, formula feeding has become a more common practice in urban communities of developing countries. However, relatively little information is available regarding formula feeding practice and its associated factors in Ethiopia, particularly in Addis Ababa. Hence, this study was aimed at assessing the prevalence of formula feeding practice and its associated factors among mothers of an infant aged 0-6 months in Addis Ababa, Ethiopia.

Methods: A community-based cross-sectional study was conducted from April-1 to May 30/2020 among 494 mothers with infants 0-6 months of age. Data were collected using a pre-tested structured questionnaire. Data were entered and cleaned by using Epi data version 3.1 and analysed by SPSS software version 25. Then data were processed by using descriptive analysis, including frequency distribution, and summary measures. The degree of association was assessed using binary logistic regression analysis. $P$-value $<0.05$ was considered statistically significant.
\end{abstract}

Result: The prevalence of formula feeding and pre-lacteal feeding practice was 46.2 and $34.4 \%$, respectively. Educational status with a diploma and above $(A O R=3.09,95 \% \mathrm{Cl}: 1.56-6.14)$, delivery by cesarean section $(\mathrm{AOR}=$ $6.13,95 \% \mathrm{Cl}: 4.01-9.37$ ), pre-lacteal feeding practice ( $\mathrm{AOR}=7.61,95 \% \mathrm{Cl}: 4.11-11.06$ ), and delayed initiation of breastfeeding (after $1 \mathrm{~h}$ to 1 day ( $\mathrm{AOR}=3.43,95 \% \mathrm{Cl}$ : 1.59-7.40), after 1 day to 3 days ( $\mathrm{AOR}=3.71,95 \% \mathrm{Cl}: 1.51-9.41$ ), and after 3 days (AOR $=5.41,95 \% \mathrm{Cl}: 2.15-13.60)$ ) were significantly associated with formula feeding practice.

\footnotetext{
* Correspondence: mitkumamo@gmail.com

${ }^{2}$ Department of Biomedical Sciences, College of Medicine and Health Sciences, Wolkite University, P.O. Box 07, Wolkite, Ethiopia

Full list of author information is available at the end of the article
}

C C The Author(s). 2021 Open Access This article is licensed under a Creative Commons Attribution 4.0 International License, which permits use, sharing, adaptation, distribution and reproduction in any medium or format, as long as you give appropriate credit to the original author(s) and the source, provide a link to the Creative Commons licence, and indicate if changes were made. The images or other third party material in this article are included in the article's Creative Commons licence, unless indicated otherwise in a credit line to the material. If material is not included in the article's Creative Commons licence and your intended use is not permitted by statutory regulation or exceeds the permitted use, you will need to obtain permission directly from the copyright holder. To view a copy of this licence, visit http://creativecommons.org/licenses/by/4.0/ The Creative Commons Public Domain Dedication waiver (http://creativecommons.org/publicdomain/zero/1.0/) applies to the data made available in this article, unless otherwise stated in a credit line to the data. 
(Continued from previous page)

Conclusions: Nearly half of the participants were practiced formula-feeding for their infant. Educational status of mothers, the timing of initiation of breastfeeding, delivery by cesarean section, and pre-lacteal feeding practice were significantly associated with formula feeding practice. Therefore, early initiation of breastfeeding, educating mothers about the risks associated with pre-lacteal feeding, and supporting mothers who gave birth by cesarean section for exclusive breastfeeding should be encouraged at the community and institutional levels.

Keywords: Formula, Breastfeeding, Predictor, Ethiopia

\section{Background}

Infants are in a state of rapid growth and development; the growth rate is most rapid during the first 4 to 6 months of life. Optimal infant and young child feeding practices rank among the most effective interventions to improve child health $[1,2]$.

The World Health Organization (WHO) [3] and the American Academy of Pediatrics (AAP) [4] recommends exclusive breastfeeding for the first 6 months of life with a continuation of breastfeeding while gradually introducing solid foods into the infant's diet for 1 year or longer as mutually desired by mother and infant. In 2016, the United Nations (UN) Office of the high commissioner of human rights declared that breastfeeding is a human rights issue for both mothers and children and should be protected and promoted for the benefit of both. The introduction of local, nutrient-rich complementary foods thereafter with continued breastfeeding for 2 years of age or beyond is recommended $[5,6]$.

Despite, the recommendations that babies should be exclusively breastfed for the first 6 months, less than $40 \%$ of infants below this age are exclusively breastfeeding worldwide. This is due to the impacts of globalization, increasing availability of formula milk in the supermarket, and promotion of formula milk by advertising on different media, the proportion, and duration of breastfeeding are declining and being replaced by formula feeding.

Lack of breastfeeding and especially lack of exclusive breastfeeding during the first half-year of life are important risk factors for infant and childhood morbidity and mortality [7, 8]. United Nations international children's emergency fund (UNICEF) states that the provision of supplemental formulas can increase infant mortality by as much as 25 times [9]. Infants on formula feeding are not only deprived of the benefits of breast milk but also to be affected by acute respiratory infections (ARI), otitis media, allergies, gastroenteritis, diarrhea, pneumonia, diabetes mellitus, decreased cognitive development, increase risk of obesity, and sudden infant death syndrome [2, 8-10].

Formula feeding has become a common practice in developed countries and urban communities in developing countries. Today there is a shift from exclusive breastfeeding practice towards the introduction of bottle-feeding. The increasing incidence of bottle feeding in developing countries particularly in Africa reflects the absorption of the western way of life [11].

Starting from 2016, the Ethiopian government has implemented several directives such as the "Infant Formula and Follow-up Formula Directive No. 30/2016" and the "Food Advertisement Directive 33/2016" to encourage breastfeeding by restricting the promotion of formula feeding practice [12]. However, the proportions of mothers who still breast-feed their child are considerably low particularly among women of the capital city, Addis Ababa [13]. According to the Ethiopian Demographic and Health Survey (EDHS) 2016 report, only 58\% of infants less than 6 months were exclusively breastfed [14]. Formula feeding was $30 \%$ among the age of up to 1 month, it was $45 \%$ between two and 3 months and it increased to $68 \%$ in the infants from four to 5 months [2].

Nowadays there are different mechanisms applying in formula milk promotion by advertising on different media including by training health care providers. Due to these, intervention should be done to promote exclusive breastfeeding than infant formula at international and national levels especially in urban communities of Ethiopia. Hence, the study was conducted to assess the formula feeding practice and its associated factors among mothers with infants aged 0-6 months in Addis Ababa city, the capital city of Ethiopia.

The finding of this study will provide relevant updated information regarding the formula feeding practice and its associated factors, which is helpful for policymakers and other stakeholders to develop appropriate strategies and interventions for promoting and maintaining exclusive breastfeeding practices for the first 6 months of an infant's life. It is also hoped that the study will provide baseline data for further research investigation on the area of this study.

\section{Methods}

\section{Study setting and design}

A community-based cross-sectional study was conducted in Addis Ababa, the capital city of Ethiopia from April 1 to May 30/2020. Addis Ababa city holds a total area of $527 \mathrm{~km}^{2}$ and contains 10 sub-cities and 116 woredas. The city has an estimated population of 4,793,699 
and each woreda contained an estimated 479,370 populations on average [15].

\section{Study population and sampling techniques}

All mothers who had infants less than 6 months old and lives at randomly selected woreda were eligible for the study whereas mothers, who were critically ill or unable to respond due to serious illness during the data collection period and no other family members living with her, were excluded from the study.

The required sample size was determined using a single population proportion formula by taking the proportion of formula feeding as 68\% [2], 95\% confidence interval, $5 \%$ level of precision, and a design effect of 1.5 . Hence, the final sample size was 500 .

\section{Sampling procedures}

A multistage sampling technique was used for selecting the study participants. Initially, Gulele, Arada, and Lideta sub-cities (each of which contains 10 woredas) were randomly selected. Then using a simple random sampling technique three woredas were selected from each selected sub-city. Then, the number of mothers who were selected from each selected woreda was determined proportionally. Finally, to select the study participants from each selected woreda, a systematic random sampling technique was used by using the list of mothers from the Epi registration book from each woreda health office (Additional file 1: Fig. S1).

\section{Data collection procedures and operational definitions}

Data were collected by using a pre-tested structured questionnaire which was taken from previously published literature on a similar title in which the cultural and socioeconomic characteristics of study participants were similar to the target population of this study [2]. The questionnaire consists of socio-demography characteristics, maternal health service utilization, and infantrelated characteristics. Data were collected at the household level from mothers with infants 0-6 months of age and who resides at selected woreda in Gulele, Arada, and Lideta sub-cities. The questionnaire was initially prepared in English and translated to Amharic (local language) and then back to English with an expert who has a good ability of the two languages to maintain its consistency. Then the final Amharic form of the questionnaire was used to collect the data.

Prior to the actual data collection, the questionnaire was pretested on $10 \%$ (50) of the sample size in woreda 03 under Yeka sub-city which was not part of the actual data collection area. Based on the pre-test some modifications have been done to the questionnaire.

Six data collectors (urban health extension workers) and three supervisors (public health professionals) were recruited. One day of training was given for data collectors and supervisors by the investigators on the objectives of the study, data collection procedures, data collection tools, and confidentiality of information. The principal investigator coordinates the overall process of data collection and the activity of the whole study. The data collection procedures were checked frequently through supervision by the investigators and supervisors for its consistency. Moreover, the collected data were checked daily to safeguard its completeness.

In this study, the formula-feeding practice was defined as a positive answer to the question "Did you fed your child any formula feeding as a substitute or supplement to breastfeeding?" Pre-lacteal feeding is also assessed by asking "What did you start to feed your child the day he/she has born?" The mothers who answered "other than breast milk" to the question were considered a mother who practiced pre-lacteal feeding. The infant's birth weight was recorded by reviewing the registration book in the delivery room from the health facility in which the mother was delivered.

\section{Operational definition}

Birth weight of infants: Low birth weight (birth weight $<2500 \mathrm{~g})$; normal birth weight $(2500 \mathrm{~g} \leq$ birth weight < $4000 \mathrm{~g}$ ); and over birth weight (birth weight $\geq 4000 \mathrm{~g}$ ) [16].

Formula feeding practice: Feeding of an infant less than 6 months old with formula food or bottle feeding as a substitute for or supplement to breastfeeding [2].

Pre-lacteal feeding: Feeding of an infant with any fluid or semisolid food before the mother has begun to breastfeed [17].

Timely initiation of breast milk: Initiation of breast milk within 1 hour of delivery [18].

Woreda: The third-level administrative divisions of Ethiopia which further subdivided into several kebele or neighborhood associations.

\section{Data processing and analysis}

The collected data were checked manually for its completeness and consistency. Then the data were coded and entered into Epi-data version 3.1 and double enters by another person for consistency. Finally, the data were exported to SPSS-version 25 for further analysis. Multicolinearity among selected independent variables was checked via "Variance inflation factor (VIF) and Tolerance" and all variables were with less than 3 and above 0.2 VIF and tolerance, respectively. The data were processed by using descriptive analysis, including frequency distribution, and summary measures. Categorical variables were stated as number (percentage) whereas the continuous data as means \pm standard deviation (SD).

To determine the independently associated variables, associations were investigated using binary logistic 
regression analysis. All independent variables with $p$ value $<0.25$ in the unadjusted model were selected as a candidate for multivariable analysis to control the effect of confounding variables. Model fitting at the "hosemer and lemeshew test" was done to check model fitness at a non-significant level in multivariable analysis. Then the degree of associations was expressed by using the odds ratio (ORs) with $95 \%$ CI. $P$-value $<0.05$ was considered statistically significant.

\section{Results}

\section{Socio-demographic characteristics of the study participants}

A total of 500 mothers were invited and 494 of them volunteered to participate in the study making the response rate $98.8 \%$. The mean age $( \pm \mathrm{SD})$ of the respondents was $30.11( \pm 5.73)$ years. More than half $(60.1 \%)$ of the respondents were in the age group 25-34 years. The majority (96.2\%) of participants were married, 198 (40.1\%) were housewives, and 164 (33.2\%) were with educational status of degree and above (Table 1).

\section{Health service utilization of mothers and infant related characteristics}

Among the total of the respondents, 298 (60.3\%) were multipara, 489 (99.0\%) were received antenatal care (ANC) services during pregnancy, and all participants gave birth at health facilities. The majority (93.5\%) of the participants received postnatal care (PNC) counseling about breastfeeding and complementary feeding. Regarding infants related characteristics, more than half $(56.3 \%)$ of the infants were in the age group 4-6 months, 422 (85.4\%) had normal birth weight, and 330 (66.8\%) started breastfeeding within $1 \mathrm{~h}$ of delivery (Table 2 ).
Formula feeding practice among the study participants In this study, the prevalence of formula feeding was 46.2\% (95\% CI: 41.3-49.7\%). Among the infants with formula feeding, more than half $(54.4 \%)$ were males. The prevalence of formula feeding practice was higher among infants aged $2-3$ months (52\%), low birth weight $18(56.3 \%)$, delivery by cesarean section 143 (71.5\%), infants with pre-lacteal feeding 145 (85.3\%), and infants who started breastfeeding after 3 days of delivery 16 (80\%) (Fig. 1).

\section{Awareness of mothers towards infant formula feeding}

Among the study participants, 412 (83.4\%) have heard about infant formula feeding. The most frequent source of information for formula feeding practice was mass media, i.e. television and radio 194 (47.1\%); other sources were relatives 111 (26.9), health facility staff 85 (20.6), and supermarket/pharmacy staff 22 (5.4\%). The most common reported reason behind infant formula feeding practice among mothers was insufficient breast milk production $181(79.4 \%)$, a mother being sick 36 (15.8\%), and a baby being sick $11(4.8 \%)$.

\section{Factors associated with formula feeding practice}

On a multivariable logistic regression analysis educational status of mothers with a diploma and above (AOR $=3.09,95 \%$ CI: $1.56-6.14)$, the timing of initiation of breastfeeding (after $1 \mathrm{~h}$ to 1 day (AOR $=3.43,95 \% \mathrm{CI}$ : $1.59-7.40)$, after 1 day to 3 days $(\mathrm{AOR}=3.71,95 \% \mathrm{CI}$ : $1.51-9.41$ ), and after 3 days (AOR $=5.41,95 \%$ CI: $2.15-$ $13.60)$ ), delivery by cesarean section ( $\mathrm{AOR}=6.13,95 \%$ CI: 4.01-9.37), and presence of pre-lacteal feeding (AOR $=7.61,95 \%$ CI: $4.11-11.06$ ) were significantly associated with formula feeding practice (Table 3).

Table 1 Socio-demographic characteristics of mothers having infants less than 6 months old, in Addis Ababa city, Ethiopia, 2020 $(N=494)$

\begin{tabular}{llll}
\hline Variables & Category & Frequency $(\boldsymbol{N}=\mathbf{4 9 4})$ & Percent (\%) \\
\hline Age (years) & $<25$ & 64 & 13.0 \\
& $25-34$ & 297 & 60.1 \\
Educational status & $\geq 35$ & 133 & 26.9 \\
& Primary & 77 & 15.6 \\
& Secondary & 112 & 22.7 \\
Cccupational status & Certificate/diploma & 141 & 28.5 \\
& Degree and above & 164 & 33.2 \\
& Private employee & 198 & 40.1 \\
Current marital Status & Government employee & 169 & 34.2 \\
& Others & 110 & 22.3 \\
& Married & 17 & 3.4 \\
\hline
\end{tabular}


Table 2 Health service utilization among mothers having infants less than 6 months old, and infants related characteristics in Addis Ababa, Ethiopia, $2020(n=494)$

\begin{tabular}{|c|c|c|c|}
\hline Variables & Categories & Frequency & Percent \\
\hline \multirow[t]{2}{*}{ Parity } & Prim- Para & 196 & 39.7 \\
\hline & Multi-para & 298 & 60.3 \\
\hline \multirow[t]{2}{*}{ ANC follow-up } & No & 5 & 1.0 \\
\hline & Yes & 489 & 99.0 \\
\hline \multirow[t]{2}{*}{ Number of ANC visit } & $<3$ & 49 & 10.0 \\
\hline & $\geq 3$ & 440 & 90.0 \\
\hline \multirow[t]{2}{*}{ Place of ANC follow-up } & Public health institution & 261 & 53.4 \\
\hline & Private health institution & 228 & 46.6 \\
\hline \multirow[t]{2}{*}{ Place of delivery } & Public health institution & 251 & 50.8 \\
\hline & Private health institution & 243 & 49.2 \\
\hline \multirow[t]{2}{*}{ Mode of delivery } & Spontaneous/vaginal & 294 & 59.5 \\
\hline & Cesarean section & 200 & 40.5 \\
\hline \multirow[t]{3}{*}{ Age of child (months) } & $<2$ & 166 & 33.6 \\
\hline & $2-3$ & 50 & 10.1 \\
\hline & $4-6$ & 278 & 56.3 \\
\hline \multirow[t]{2}{*}{ Sex of the child } & Male & 284 & 57.5 \\
\hline & Female & 210 & 42.5 \\
\hline \multirow[t]{3}{*}{ Weight of the child } & Under weight & 32 & 6.5 \\
\hline & Normal weight & 422 & 85.4 \\
\hline & Over weight & 40 & 8.1 \\
\hline \multirow[t]{4}{*}{ Timely initiation of breast feeding } & Within $1 \mathrm{~h}$ & 330 & 66.8 \\
\hline & 1 h -1 day & 75 & 15.2 \\
\hline & 1 day-3 days & 69 & 14.0 \\
\hline & Above 3 days & 20 & 4.0 \\
\hline \multirow[t]{2}{*}{ Pre-lacteal feeding } & Yes & 170 & 34.4 \\
\hline & No & 324 & 65.6 \\
\hline
\end{tabular}

ANC Antenatal care

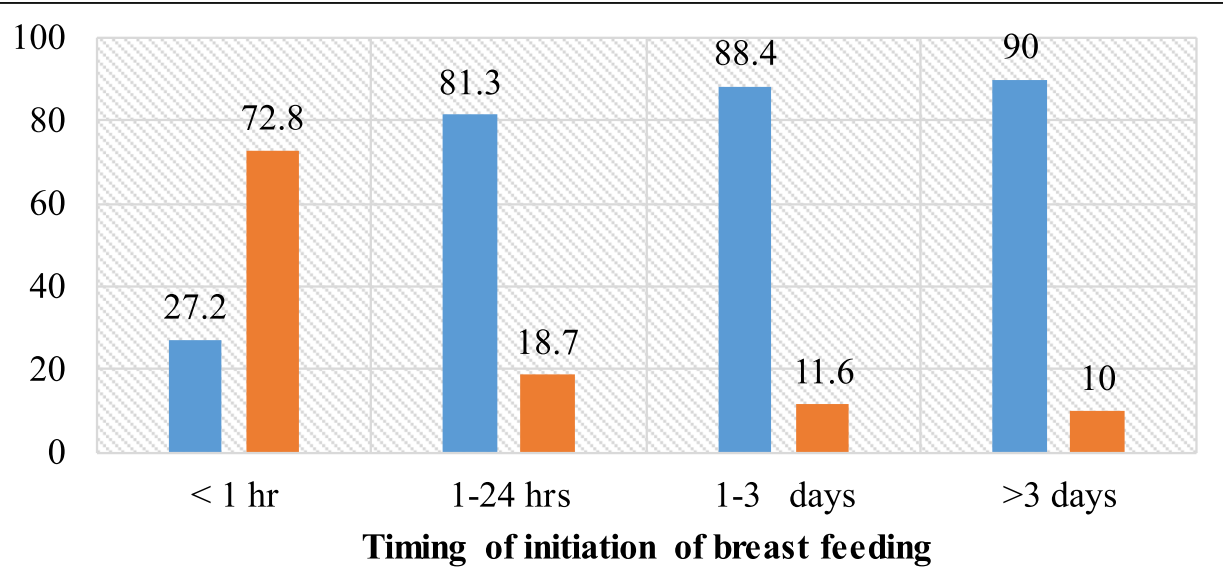

Formula feeding practice yes $\quad$ Formula feeding practice no

Fig. 1 Percentage of formula feeding practice based on timing of initiation of breastfeeding among mothers having infants less than 6 months old in Addis Ababa, Ethiopia, 2020 
Table 3 Binary logistic regression analyses of factors associated with formula feeding among mothers with infants less than 6 months old in Addis Ababa, Ethiopia, 2020 ( $N=494)$

\begin{tabular}{|c|c|c|c|c|}
\hline \multirow[t]{2}{*}{ Variables } & \multicolumn{4}{|c|}{ Formula feeding practice } \\
\hline & Yes (\%) & No (\%) & COR $(95 \% \mathrm{Cl})$ & AOR $(95 \% \mathrm{Cl})$ \\
\hline \multicolumn{5}{|l|}{ Education } \\
\hline Primary school & $17(22.1)$ & $60(77.9)$ & 1 & 1 \\
\hline Secondary school & $39(34.8)$ & $73(65.2)$ & $1.89(1.04-3.61)^{*}$ & $1.77(0.93-3.36)$ \\
\hline Diploma \& above & $172(56.4)$ & $133(43.6)$ & $4.56(2.28-7.46)^{*}$ & $3.09(1.56-6.14)^{*}$ \\
\hline \multicolumn{5}{|l|}{ Occupation } \\
\hline House wife & $74(37.4)$ & $124(62.6)$ & 1 & 1 \\
\hline Government & $56(50.9)$ & $54(49.1)$ & $1.74(1.14-2.94)^{*}$ & $1.30(0.73-2.33)$ \\
\hline Private and others & $98(52.7)$ & $88(47.3)$ & $1.87(1.25-2.83)^{*}$ & $1.59(.98-2.56)$ \\
\hline \multicolumn{5}{|l|}{ Marital status } \\
\hline Married & $224(47.2)$ & $251(52.8)$ & $3.35(1.13-10.53)^{*}$ & $2.79(0.84-9.33)$ \\
\hline Single/divorced & $4(21.1)$ & $15(78.9)$ & 1 & 1 \\
\hline \multicolumn{5}{|l|}{ Place of ANC } \\
\hline Public & $100(38.3)$ & $161(61.7)$ & 1 & 1 \\
\hline Private & $128(56.1)$ & $100(43.9)$ & $2.06(0.51-4.41)$ & $1.60(0.83-3.09)$ \\
\hline \multicolumn{5}{|l|}{ Number of ANC visit } \\
\hline$<3$ & $32(65.3)$ & $17(34.7)$ & 1 & 1 \\
\hline$\geq 3$ & $196(44.5)$ & $244(55.5)$ & $0.43(0.01-0.437)^{*}$ & $0.60(0.09-4.26)$ \\
\hline \multicolumn{5}{|l|}{ Place of delivery } \\
\hline Public institutions & $95(37.8)$ & $156(62.2)$ & 1 & 1 \\
\hline Private institutions & $133(54.7)$ & $110(45.3)$ & $1.99(1.87-2.85)^{*}$ & $1.08(0.45-1.72)$ \\
\hline \multicolumn{5}{|l|}{ Mode of delivery } \\
\hline Normal/vaginal & $85(28.9)$ & $209(71.1)$ & 1 & 1 \\
\hline Cesarean section & $143(71.5)$ & $57(28.5)$ & $6.17(4.35-9.09)^{*}$ & $6.13(4.01-9.37)^{*}$ \\
\hline \multicolumn{5}{|c|}{ Timing of initiation of breastfeeding } \\
\hline Within $1 \mathrm{~h}$ & $110(33.3)$ & $220(66.7)$ & 1 & 1 \\
\hline After $1 \mathrm{~h}$ to 1 day & $50(66.7)$ & $25(33.3)$ & $4.00(6.19-21.86)^{*}$ & $3.43(1.59-7.40)^{*}$ \\
\hline After 1 day to 3 days & $52(75.4)$ & $17(24.6)$ & $6.12(9.37-44.27)^{*}$ & $3.71(1.51-9.41)^{*}$ \\
\hline After 3 days & $16(80.0)$ & $4(20.0)$ & $8.00(5.46-25.71)^{*}$ & $5.41(2.15-13.60)^{*}$ \\
\hline \multicolumn{5}{|l|}{ Pre-lacteal feeding } \\
\hline Yes & $145(85.3)$ & $25(14.7)$ & $11.84(7.12-25.59)^{*}$ & $7.61(4.11-11.06)^{*}$ \\
\hline No & $83(25.6)$ & $241(74.4)$ & 1 & 1 \\
\hline \multicolumn{5}{|l|}{ Age of the child } \\
\hline$<2$ month & $63(38.0)$ & $103(62.0)$ & 1 & 1 \\
\hline $2-3$ months & $26(52.0)$ & $24(48.0)$ & $1.77(1.62-2.77)^{*}$ & $2.17(0.98-3.14)$ \\
\hline $4-6$ months & $139(50.0)$ & $139(50.0)$ & $1.63(1.29-3.11)^{*}$ & $1.92(0.74-3.09)$ \\
\hline
\end{tabular}

*Significant at a $p$-value of $<0.05, B F$ Breastfeeding, ANC Antenatal care, C/S Cesarean section

\section{Discussion}

This study has assessed the prevalence of formula feeding practice and associated factors among mothers with infants $0-6$ months of age. Accordingly, the study found that $46.2 \%$ of mothers in the study area used formula feeding, $34.4 \%$ fed their infant pre-lacteal fluid. It was also found that the educational status of mothers, timing of initiation breastfeeding, pre-lacteal feeding, and delivery by cesarean section were significantly associated with formula feeding practices.

The prevalence of formula feeding practice in this study was similar to the EDHS 2011 result [19], the study in Eastern Ethiopia [20], and Jimma, Southwest Ethiopia [2]. However, this was higher than the findings 
from the studies conducted at Holeta (19.6\%) [21], Gozamin, Northwest Ethiopia [22], Bodity, Southern Ethiopia [23], and Shashemene (20.9\%) [24], but lower than the study conducted in Agaro, Southwest Ethiopia [25], and Harar [18]. The reasons for this difference in the prevalence of formula feeding practice may be due to variations in the study setting, sociocultural characteristics of participants, employment status of participants, availability of health care services, and health service utilization. Due to the urban area of the study, the participants in this study may be more likely to be government employees as compared to the study elsewhere in the rural area and hence the prevalence of formula feeding practice may be higher.

Concerning factors associated with formula feeding, this study found that mothers with an educational level of college diploma and above were more likely to practice formula feed for their child as compared to those with primary education and below. While this finding is comparable with similar studies conducted in Agaro, Southwest Ethiopia [25], Jimma, Southwest Ethiopia [2], and Cameroon [26], it is contrary to a study conducted in Indonesia [9] where educated mothers were $39 \%$ less likely to formula feed their infants. The reason for this discrepancy may be related to the methodology of the studies, classification of educational status, or the cultural differences of the study subjects.

Mode of delivery was also significantly associated with the formula-feeding practice, as mothers who gave birth by cesarean section were more likely to feed formula as compared to those who gave birth vaginally. This is in agreement with a similar study conducted in Bahirdar [27], Addis Ababa [28], and Egypt [29] where cesarean delivery was significantly associated with formula feeding practice. This may be due to post-operative conditions, as mothers with cesarean sections were less likely to have had skin-to-skin contact with their infants and felt fatigued and less relaxed after birth in the delivery room. This causes improper breast stimulation and emptying which in turn reduce maternal milk secretion and cause the introduction of formula feeding.

Contrary to this finding, another study conducted in a group of mothers in Egypt showed that cesarean delivery was $41.9 \%$ less likely associated with formula feeding practice [11]. The study in Debre Tabor town, Northwest Ethiopia, also found that mothers, who gave birth vaginally, were two times more likely to practice formula feeding than mothers who gave birth with cesarean section [30]. The reason for this discrepancy may be related to the methodology, period of the study, classification of mothers who delivered by cesarean section (mixed feeding group and exclusive formula feeding group), and the cultural differences of the study subjects.
Another predictor for formula feeding practice in this study was the timely initiation of breast milk. Mothers who initiated breastfeeding after 1 hour to 1 day of delivery were three times more likely to practice formula feeding compared to those who initiated breastfeeding within 1 hour. Similarly, mothers who initiated breastfeeding after 1 day up to 3 days and after 3 days were approximately four and five times more likely to practice formula feeding compared to those who initiated breastfeeding within $1 \mathrm{~h}$, respectively. This finding was in agreement with studies from Hossana [31], Afar region [32], and Offa district, Southern Ethiopia [17]. The possible reason for this might be due to the fact that mothers who practiced early initiation of breastfeeding may have relatively good knowledge, attitude, and practice towards exclusive breastfeeding and also may have a better understanding about the risk of formula feeding for infants under the age of 6 months. When the time interval between delivery and initiation of breastfeeding is increases, there is a chance for the initiation of prelacteal feeding practice which in turn leads to decreased newborn-mother bonding and then inadequate maternal breast milk secretion.

It was also likely that the difference in the practice of formula-feeding may result from the difference in prelacteal feeding. Compared to mothers who didn't give pre-lacteal feeds for their infant, mothers who gave prelacteal feeding were eight times more likely to practice formula-feeding. This finding is consistent with the findings of the studies in Raya Kobo district, North Eastern Ethiopia [33], Debre Markos [34], and Motta, Northwest Ethiopia [35]. This may be because pre-lacteal feeding cause delays in the need of an infant's immediate breastfeeding and decreases the infant's suckling and breast stimulation activity which in turn leads to inadequate milk production. The decrease in milk production will lead mothers to introduce supplementary foods for their infants and the addition of this supplementary formula may cause more and more reduction in milk production.

The study has some limitations. Due to the crosssectional nature of the study design, the cause and effect relationship of events cannot be ascertained; moreover, as data were collected based on the mother's perspective and self-reports rather than the practice being observed, the recall and social desirability biases may represent further limitations of the study.

\section{Conclusion}

Nearly half of the participants had formula-feeding practiced and one-third of participants were given pre-lacteal feeding for their infants. Educational status of mothers, the timing of initiation of breastfeeding, mode of delivery, and pre-lacteal feeding practice were found to be significantly and independently associated with formula 
feeding practice. Therefore, early initiation of breastfeeding, educating mothers about the risks associated with pre-lacteal feeding, and supporting mothers who gave birth by cesarean section for exclusive breastfeeding should be encouraged at the community and institutional levels.

\section{Abbreviations}

AAP: American academy of pediatrics; ANC: Antenatal care; AOR: Adjusted odds ratio; ART: Acute respiratory infections; COR: Crude odds ratio; EBF: Exclusive breastfeeding; EDHS: Ethiopian demographic and health survey; IRB: Institutional review board; PNC: Postnatal care; WHO: World health Organization

\section{Supplementary Information}

The online version contains supplementary material available at https://doi. org/10.1186/s13052-021-01010-x.

\section{Additional file 1: Fig. S1: Schematic representation sampling} procedure for assessing formula feeding practice in Addis Ababa city, 2020

\section{Acknowledgments}

We would like to extend our deepest appreciation to Debre Birhan University for offering the opportunity and technical support to undertake the study. We are also grateful to thank the selected sub-cities and woredas administrative offices and health offices for their cooperation and technical support. Finally, would like to thank data collectors, supervisors and study participants for their cooperation thought the study.

\section{Authors' contributions}

AAT: Develop proposal and data collection sheet, give training for data collectors, collected data, analyzed it and wrote the draft of the manuscript. WA, MMT, YGB and BZ: Conceived the study, supervised the data collection and reviewed the draft of the manuscript. All authors read and approved the final draft of the manuscript.

\section{Funding}

The authors received no financial support for this study and the study was funded by the authors.

\section{Availability of data and materials}

The datasets used and/or analyzed during the current study are available from the corresponding author on reasonable request.

\section{Declarations}

\section{Ethics approval and consent to participate}

Ethical clearance was obtained from the Ethical Review Board (IRB) Debre Berhan University. The official letters were written by Addis Ababa public health research and emergency management directorate to each sub-city administration and health office to get permission and supportive letter. Before the actual data collection, written informed consent was obtained from the study participants. All the rights of the study subjects autonomy (personal decision), non-maleficence (not to harm), and justice (fairness) were kept during the study. Furthermore, the confidentiality of the individual information was assured.

\section{Consent for publication}

Not applicable.

\section{Competing interests}

The authors declare that they have no competing interests.

\section{Author details}

${ }^{1}$ Department of Public Health, College of Health Science, Debre Berhan University, Debre Berhan, Ethiopia. ${ }^{2}$ Department of Biomedical Sciences, College of Medicine and Health Sciences, Wolkite University, P.O. Box 07,
Wolkite, Ethiopia. ${ }^{3}$ USAID HIV Control Grant, Addis Ababa, Ethiopia. ${ }^{4} \mathrm{HaSET}$ Maternal and Child Health Research Program, Shewarobit Field Office, Shewarobit, Ethiopia.

Received: 26 November 2020 Accepted: 26 February 2021

Published online: 09 March 2021

\section{References}

1. Bhandari N, Chowdhury R. Infant and young child feeding. Proc Indian Natl Sci Acad. 2016;82(5):1507-17. https://doi.org/10.16943/ptinsa/2016/48883.

2. Abebe L, Aman M, Asfaw S, Gebreyesus H, Teweldemedhin M, Mamo A. Formula-feeding practice and associated factors among urban and rural mothers with infants 0-6 months of age: a comparative study in Jimma zone Western Ethiopia. BMC Pediatr. 2019;19(1):1-10. Available froom: https://doi.org/https://doi.org/10.1186/s12887-019-1789-8.

3. World Health Organization, Department of Nutrition for Health and Development (NHD). The optimal duration of exclusive breastfeeding report of an expert consultation Geneva, Switzerland 28-30 march 2001. https:// www.who.int/nutrition/publications/optimal_duration_of_exc_bfeeding_ report_eng.pdf

4. American Academy of Pediatrics Section on Breastfeeding. Breastfeeding and the use of human Milk. Pediatrics. 2012;129:e827-41. [PubMed: 22371471. https://doi.org/10.1542/peds.2011-3552.

5. UN human rights experts urge countries to increase efforts to protect, promote and support breastfeeding, and end inappropriate marketing of breast-milk substitutes. Geneva; 2016. https://www.who.int/nutrition/topics/ UNhumanrights-statement-breastfeeding-rights/en/. Accessed 21 Mar 2020.

6. Bonia K, Twells L, Halfyard B, Ludlow V, Newhook LA, Murphy-Goodridge J. A qualitative study exploring factors associated with mothers' decisions to formula-feed their infants in Newfoundland and Labrador, Canada. BMC Public Health. 2013;13(645):1-9. http://www.biomedcentral.com/1471-24 $58 / 13 / 645$.

7. World Health Organization. Infant and young child feeding: a tool for assessing national practices, policies and programmes. Geneva; 2003. https://apps.who.int/iris/bitstream/handle/10665/42794/9241562544. pdf? sequence=1\&isAllowed=y. Accessed 28 Mar 2020.

8. Appleton J, Laws R, Russell CG, Fowler C, Campbell KJ, Denney-Wilson E. Infant formula feeding practices and the role of advice and support: An exploratory qualitative study. BMC Pediatr. 2018;18(1). https://doi.org/10.11 86/s12887-017-0977-7.

9. Nuralita AY, Murti B, Pamungkasari EP. Factors affecting infant formula feeding in infants aged 0-6 months in Sukoharjo, Central Java. J Matern Child Health 2017;2(3):270-283. https://doi.org/https://doi.org/10.26911/ thejmch.2017.02.03.08.

10. Setegn T, Belachew T, Gerbaba M, Deribe K, Deribew A, Biadgilign S. Factors associated with exclusive breastfeeding practices among mothers in Goba district, south East Ethiopia: a cross-sectional study. Int Breastfeed J. 2012; 7(1):17 http://www.internationalbreastfeedingjournal.com/content/7/1/17.

11. Tawfik S, Saied D, Mostafa O, Salem M, Habib E. Formula feeding and associated factors among a Group of Egyptian Mothers. Open Access Macedonian J Med Sci 2019;7(11):1854-1859. https://doi.org/https://doi. org/10.3889/oamjms.2019.462. https://www.ncbi.nlm.nih.gov/pmc/articles/ PMC6614267/pdf/OAMJMS-7-1854.pdf

12. Ethiopian Food, Medicine and Health Care Administration and Infant Formula and Follow-up Control Authority Formula Directive. http://efmhaca. hcmisonline.org/wp-content/uploads/2019/03/INFANT-AND-FOLLOW-UPFORMULA-DIRECTIVE.pdf. Accessed 28 Mar 2020

13. Shifraw T, Worku A, Berhane Y. Factors associated exclusive breastfeeding practices of urban women in Addis Ababa public health centers, Ethiopia: a cross sectional study. Int Breastfeed J. 2015;10(1):22. https://doi.org/10.1186/ s13006-015-0047-4.

14. Central statistical agency (CSA) [Ethiopia] and ICF. Ethiopia demographic and health survey 2016. Addis Ababa, Ethiopia, and Rockville, Maryland, USA: CSA and ICF; 2016. https://dhsprogram.com/pubs/pdf/SR241/SR241.pdf

15. Addis Ababa Population 2020 (Demographics, Maps, Graphs)- https:// worldpopulationreview.com/world-cities/addis-ababa-population

16. Abubakari A., Kynast-Wolf G, Jahn, A. Prevalence of abnormal birth weight and related factors in northern region, Ghana. BMC Pregnancy Childbirth, 2015, 15:335. https://doi.org/https://doi.org/10.1186/s12884-015-0790-y.

17. Lenja A, Demissie T, Yohannes B, Yohannis M. Determinants of exclusive breastfeeding practice to infants aged less than six months in Offa district, 
southern Ethiopia: a cross-sectional study. Int Breastfeed J 2016;11(32):1-7. Available from: http://dx.doi.org/https://doi.org/10.1186/s13006-016-0091-8.

18. Dibisa TM, Sintayehu Y. Exclusive breast feeding and its associated factors among mothers of < 12 months old child in Harar town, eastern Ethiopia: a cross-sectional study. Pediatr Health Med Ther. 2020;11:145. DOl https://doi. org/https://doi.org/10.2147/PHMT.S253974

19. Central Statistical Agency [Ethiopia], ICF International. Ethiopia Demographic and Health Survey 2011. 2012;1-452. https://dhsprogram.com/pubs/pdf/FR2 55/FR255.pdf.

20. Abera K. Infant and young child feeding practices among mothers living in Harar, Ethiopia. Bull Health Sci. 2012;4:66-78.

21. Kebebe T, Assaye $H$. Intention, magnitude and factors associated with bottle feeding among mothers of 0-23 months old children in Holeta town, Central Ethiopia: a cross sectional study. BMC Nutr. 2017;3(53):1-7. https://doi.org/10.1186/s40795-017-0174-y.

22. Hunegnaw M.T., Gezie L.D., Teferra A.S. Exclusive breastfeeding and associated factors among mothers in Gozamin district, Northwest Ethiopia: a community based cross-sectional study. Int Breastfeed J 12, 30 (2017). https://doi.org/https://doi.org/10.1186/s13006-017-0121-1.

23. Azeze GA, Gelaw KA, Gebeyehu NA, Gesese MM, Mokonnon TM. Exclusive breastfeeding practice and associated factors among mothers in Boditi Town, Wolaita Zone, Southern Ethiopia, 2018: a community-based crosssectional study. Int J Pediatr. 2019;2019:1-11.

24. Yonas F, Asnakew M, Wondafrash M, Abdulahi M. Infant and young child feeding practice status and associated factors among mothers of under 24month-old children in Shashemene Woreda, Oromia Region. Open Access Libr J. 2015;2(07):1. https://doi.org/10.4236/oalib.1101635.

25. Seid SS, Muluneh E, Sinbirro IA, Moga TT, Haso TK, Ibro SA. Utilization of bottle feeding practices and associated factors among mothers who have infant less than 12 months of age in Agaro Twon, Jimma Zone South West Ethiopia, 2018. Health Sci J. 2019;13(1):1-0. DOl: https://doi.org/10.21767/1 791-809X.1000630

26. Dapi LN, Tambe AB, Axberg F, Lundström L, Hörnell A. After giving birth to a baby, breastfeeding becomes your responsibility: Infant feeding perceptions and practices among women in Yaoundé, Bamenda and Bandja, Cameroon, Africa. Int Res J Public Environ Health. 2018;5(3):38-45. Doi.org/https://doi.org/10.15739/irjpeh.18.007

27. Seid AM, Yesuf ME, Koye DN. Prevalence of Exclusive Breastfeeding Practices and associated factors among mothers in Bahir Dar city, Northwest Ethiopia: a community based cross-sectional study. Int Breastfeed J. 2013;8(14):1-8 http://www.internationalbreastfeedingjournal. com/content/8/1/14.

28. Elyas L, Mekasha A, Admasie A, Assefa E. Exclusive breastfeeding practice and associated factors among mothers attending private pediatric and child clinics, Addis Ababa, Ethiopia: a cross-sectional study Int J Pediatri 2017 ;2017. https://doi.org/https://doi.org/10.1155/2017/8546192.

29. Kandeel WA, Rabah TM, Zeid DA, El-din EMS, Metwally AM, Shaalan A. Determinants of exclusive breastfeeding in a sample of Egyptian infants. Open Access Macedonian J Med Sci. 2018;6(10):1818-23 Available from https://www.ncbi.nlm.nih.gov/pmc/articles/PMC6236050/pdf/OAMJMS-6-181 8.pdf.

30. Arage G, Gedamu H. Exclusive breastfeeding practice and its associated factors among mothers of infants less than six months of age in Debre Tabor town, Northwest Ethiopia : a cross-sectiona study Adv Public Health 2016 1;2016. https://doi.org/https://doi.org/1 $0.1155 / 2016 / 3426249$

31. Earsido A, Abebe W, Dereje N. Prevalence and determinants of exclusive breastfeeding practices among infants in Hossana town, southern Ethiopia: a community based cross-sectional study. EC Gynaecol. 2017;3:69-79 https://www.ecronicon.com/ecgy/pdf/ECGY-04-00090.pdf

32. Liben ML, Gemechu YB, Adugnew M, Asrade A, Adamie B. Factors associated with exclusive breastfeeding practices among mothers in dubti town, afar regional state, Northeast Ethiopia: a community based crosssectional study. Int Breastfeed J 2016;11(4):1-6. Available from: http://dx.doi. org/https://doi.org/10.1186/s13006-016-0064-y

33. Legesse M, Demena M, Mesfin F, Haile D. Prelacteal feeding practices and associated factors among mothers of children aged less than 24 months in Raya kobo district, north eastern Ethiopia: a cross-sectional study. Int Breastfeed J. 2014;9(189):1-8. https://doi.org/10.1186/s13006-014-0025-2.
34. Mekuria G, Edris M. Exclusive breastfeeding and associated factors among mothers in Debre Markos, Northwest Ethiopia: a cross-sectional study. Int Breastfeed J. 2015;10(11):1-7. https://doi.org/10.1186/s13006-014-0027-0.

35. Tewabe T, Mandesh A, Gualu T, Alem G, Mekuria G, Zeleke H. Exclusive breastfeeding practice and associated factors among mothers in Motta town, east Gojjam zone, Amhara regional state, Ethiopia, 2015: a crosssectional study. Int Breastfeed J. 2017;12(12):1-7. https://doi.org/10.1186/s13 006-017-0103-3.

\section{Publisher's Note}

Springer Nature remains neutral with regard to jurisdictional claims in published maps and institutional affiliations.
Ready to submit your research? Choose BMC and benefit from:

- fast, convenient online submission

- thorough peer review by experienced researchers in your field

- rapid publication on acceptance

- support for research data, including large and complex data types

- gold Open Access which fosters wider collaboration and increased citations

- maximum visibility for your research: over $100 \mathrm{M}$ website views per year

At BMC, research is always in progress.

Learn more biomedcentral.com/submissions 